\title{
Light Competition Contributes to the Death of Masson Pines of Coniferous-Broadleaf Mixed Forests in Subtropical China
}

\author{
Yifan Song $\mathbb{D}^{\mathbb{D}}$, Ge Yan and Guangfu Zhang *
}

check for updates

Citation: Song, Y.; Yan, G.; Zhang, G. Light Competition Contributes to the Death of Masson Pines of Coniferous-Broadleaf Mixed Forests in Subtropical China. Forests 2022, 13 , 85. https://doi.org/10.3390/ f13010085

Academic Editor: Laszlo Erdos

Received: 24 November 2021

Accepted: 6 January 2022

Published: 8 January 2022

Publisher's Note: MDPI stays neutral with regard to jurisdictional claims in published maps and institutional affiliations.

Copyright: (c) 2022 by the authors. Licensee MDPI, Basel, Switzerland. This article is an open access article distributed under the terms and conditions of the Creative Commons Attribution (CC BY) license (https:// creativecommons.org/licenses/by/ $4.0 /)$.
Jiangsu Key Laboratory of Biodiversity and Biotechnology, School of Life Sciences, Nanjing Normal University, 1 Wenyuan Road, Nanjing 210023, China; 201202127@njnu.edu.cn (Y.S.); 211202140@njnu.edu.cn (G.Y.)

* Correspondence: zhangguangfu@njnu.edu.cn

\begin{abstract}
In the process of subtropical forest succession, it has long been recognized that population decline of Masson pines in coniferous-broadleaf mixed forest is caused by shading from broadleaf trees. However, little is known about the mechanism underlying the interaction between them. Here, we first chose two sets of Masson pine plots approximately aged 60 years in subtropical mountainous areas in eastern China (i.e., pure coniferous forest vs. coniferous-broadleaf mixed forest). Then, we measured and compared tree height, diameter at breast height, first branch height (FBH), live crown ratio (LCR) of Masson pines between the two sets of plots, and also determined the difference in growth performance of Masson pines relative to their neighboring broadleaf trees in the mixed forest stand. Compared with plots in pine forests, Masson pines in mixed plots had lower tree height and crown breadth, higher FBH, lower LCR, and leaf area. Furthermore, the difference of mean FBH between reference trees (Masson pines) and their neighboring trees (i.e., broadleaf trees) in mixed forest plots was greater than that in pine forest plots, and the ratio of LCR between Masson pines and their neighbors (0.46) in mixed forest was significantly smaller than in pine forest (1.05), indicating that those broadleaf trees around Masson pines probably affected their growth. The mean distance between Masson pines and neighboring trees $(1.59 \mathrm{~m})$ in mixed forest plots was significantly shorter than in pine forest plots $(2.77 \mathrm{~m})(p<0.01)$, suggesting that strong competition may occur between reference trees and their neighbors. There was a significant difference in the ratio of crown volume between reference tree Masson pine and its neighboring trees in mixed forests $(p<0.01)$, indicating that the ratio of biomass synthesis to consumption of pines was much lower than their nearby broadleaf trees in mixed forest. Our results have demonstrated for the first time that Masson pines' population decline is affected by shade-tolerant broadleaf late-successional species, which can be primarily attributed to the distinctive light transmittance of dominant species nearby (pure pine vs. mixed forest). This study provides a new perspective for future studies on the mechanism of forest succession.
\end{abstract}

Keywords: Pinus massoniana; shade; subtropics; succession; leaf area; coniferous-broadleaf mixed forest

\section{Introduction}

In general, the secondary succession of subtropical forests in eastern China can be divided into six major phases: naked lands, grasses, shrublands, coniferous forests, coniferousbroadleaf mixed forests, and deciduous (or evergreen) broadleaf forests [1]. Normally, Masson pines (Pinus massoniana) begin to occur in the stage of grasses or shrublands. The population of Masson pines then dominates in the coniferous forest stage, gradually declines in coniferous-broadleaf mixed forests, and finally sporadically appears in deciduous (or evergreen) broadleaf forests or even dies out [2]. Masson pine, as a pioneer tree in forest succession, is usually replaced by broadleaf tree species such as Liquidambar formosana, Quercus variabilis and Cyclobalanopsis glauca during late forest succession. However, why are Masson pines being replaced? The mechanism for its succession is still not clear. 
There are several possible explanations for subtropical forest succession. They can be broadly divided into two main categories concerning the aboveground part (such as light resources) and underground part (such as soil nutrient and allelopathy). First of all, as an extremely sun-acclimated tree species, Masson pine has strong tolerance to drought and is adapted to poor nutrients environment [3]. Compared with coniferous-broadleaf mixed forest, the soil in the coniferous forest during early succession remains relatively barren with low soil moisture. Masson pines grow well under such condition, and they gradually obtain an advantage over other species and, thus, develop into pure pine forest on most occasions in eastern China [4]. However, recent studies have shown that Masson pine is more suitable for growing at deep layers and fertile soil, although it can endure barren soil [5]. There are sometimes a few full-grown Masson pines in the near climax community during the late forest succession of subtropical eastern China [6]. Therefore, these studies indicate that soil condition is not the basic reason for the decline of Masson pine population. Secondly, based on allelopathy studies from laboratory, Chen et al. [7] posit adverse effects of pioneer species on later successive species in forest succession, which is similar to the results of a recently performed pot experiment [8]. Both investigations lack the support of field experiments. Moreover, this appears to contradict another popular hypothesis, i.e., the "Relay Floristics Hypothesis," that species in the early stage of succession may provide favorable conditions for those in the late stage $[9,10]$.

At present, a more prevalent explanation is that light competition is the main reason for the decline of Masson pine population. Fang and Peng [11] point out that in coniferousbroadleaf mixed forests, adult Masson pines are shaded, resulting in insufficient light resources resulting in their death. Ding and Song [6] state that the seedlings of Masson pines in coniferous-broadleaf mixed forest cannot be recruited due to lack of light in the understory. Based on our field investigation, we noticed that in a coniferous forest, Masson pines can grow tall without dying. We also found that in a coniferous-broadleaf mixed forest, there are many adult Masson pines that are significantly taller than their surrounding broadleaf tree species but with their gradual death resulting in these pines' population decline. This implies that there may very well be a new mechanism for the death of Masson pines in forest succession. Thus, there are competing hypotheses regarding the population decline of Masson pines.

We hypothesize that light competition contributes to the death of Masson pines of coniferous-broadleaf mixed forests in subtropical China. We propose that broadleaf trees in coniferous-broadleaf mixed forests cause the lower branches of nearby Masson pines to be under light stress, thus making these branches wither. With the decrease in leaf area, the pines accordingly reduce in material photosynthesis. Once the amount of produced material is lower than that of consumed material, these Masson pines will die off.

Therefore, in the current study, we chose two Masson pine stands in subtropical mountainous areas in eastern China (i.e., pure coniferous forest vs. coniferous-broadleaf mixed forest) and compared the tree height, diameter at breast height (DBH), first branch height $(\mathrm{FBH})$, and live crown ratio (LCR) of Masson pines between the two sets of plots and also determined the difference in growth performance of Masson pines relative to their neighboring broadleaf trees in the stand. This research aims at exploring the succession mechanism of subtropical forest from the perspective of the interaction between dominant tree species (conifers vs. broadleaf trees) in plant communities.

\section{Materials and Methods}

\subsection{Study Area}

According to the succession sequence of subtropical forests in eastern China, we set the study area in a coniferous forest and coniferous-broadleaf mixed forest, respectively. The coniferous-broadleaf mixed forest was chosen on the eastern slope of Purple Mountain National Forest Park in Nanjing, Jiangsu Province. The forest park is located in the eastern suburb of Nanjing City, with a geographical location of $32^{\circ} 01^{\prime} 24^{\prime \prime}-32^{\circ} 06^{\prime} 15^{\prime \prime} \mathrm{N}$, $118^{\circ} 48^{\prime} 00^{\prime \prime}-118^{\circ} 53^{\prime} 04^{\prime \prime} \mathrm{E}$, an area of $3008.8 \mathrm{hm}^{2}$, and at the highest peak $(448.8 \mathrm{~m})$ in the 
park (Figure 1). This area belongs to the national key scenic spot. Due to forest landscape transformation, impact of climate, change and pests and diseases, coniferous forests are very sporadic within the park $[12,13]$. In contrast, current vegetation mainly consists of coniferous-broadleaf mixed forest, deciduous broadleaf forest, and some evergreen and deciduous broadleaf mixed forest. Based on our field survey, we selected three locations of coniferous-broadleaf mixed forest with different dominant species in the east of Purple Mountain (Figure 1). Within Tianmuhu National Forest Park located in Liyang, which is adjacent to Nanjing, we selected a Masson pine coniferous forest (Table 1). The geographical location of the park is $31^{\circ} 09^{\prime} 25^{\prime \prime}-31^{\circ} 23^{\prime} 40^{\prime \prime} \mathrm{N}, 119^{\circ} 21^{\prime} 27^{\prime \prime}-119^{\circ} 29^{\prime} 50^{\prime \prime} \mathrm{E}$, with an area of $3759.02 \mathrm{hm}^{2}$ and the highest elevation of $508.0 \mathrm{~m}$ (Personal communication). In addition, according to forestry survey records of two forest park administrations, the age of Masson pines in the two sample sites is about 60 years.

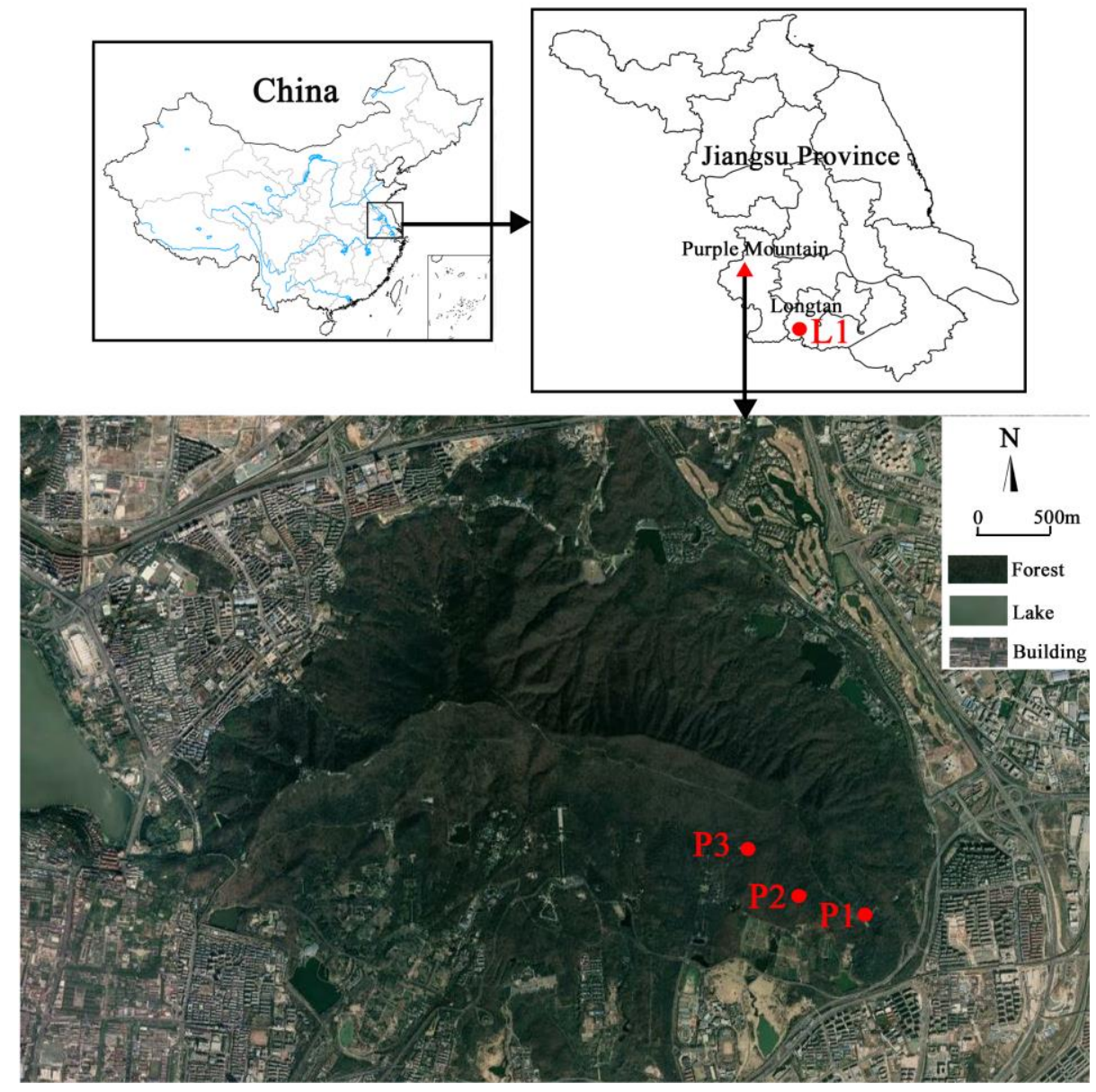

Figure 1. Location of the study area showing one pure pine forest (labelled as L1) in Longtan, Liyang and three mixed forests (P1, P2 and P3) in Purple Mountain, Nanjing, within southern Jiangsu Province, China.

The two sets of forest stands are both located in the southern mountainous area of Jiangsu Province, which is a low mountain and hills area and the soil is mainly yellow brown soil. The climate of both areas belongs to the north subtropical monsoon climate zone, with four distinct seasons, abundant sunshine and adequate rainfall. The average annual temperature is $15.4-15.6^{\circ} \mathrm{C}$. The average annual rainfall is $1050.0-1152.1 \mathrm{~mm}$. The average annual sunshine is $1932.9-2213.0 \mathrm{~h}$. The annual frost-free period is about 232-237 d [14]. 
Table 1. Data of Masson pine population and their environmental conditions in southern Jiangsu, eastern China.

\begin{tabular}{|c|c|c|c|c|c|c|c|c|c|}
\hline $\begin{array}{l}\text { Forest } \\
\text { Type }\end{array}$ & Site & $\begin{array}{l}\text { Dominant } \\
\text { Tree Species of } \\
\text { Community }\end{array}$ & $\begin{array}{c}\text { Forest } \\
\text { Age }\end{array}$ & $\begin{array}{l}\text { Elevation } \\
\text { (m) }\end{array}$ & Longitude & Latitude & Aspect $\left({ }^{\circ}\right)$ & $\begin{array}{c}\text { Slope } \\
\left({ }^{\circ}\right)\end{array}$ & $\begin{array}{c}\text { Masson } \\
\text { Pine } \\
\text { Density } \\
\left(\text { ind } / \mathrm{hm}^{2} \text { ) }\right.\end{array}$ \\
\hline Pure & $\begin{array}{l}\text { Longtan, } \\
\text { Liyang }\end{array}$ & P.ma & 60 & 85 & $31^{\circ} 14^{\prime} 51.36^{\prime \prime} \mathrm{N}$ & $119^{\circ} 29^{\prime} 56.04^{\prime \prime} \mathrm{E}$ & SE21 & 19.6 & 508 \\
\hline Mixed I & $\begin{array}{l}\text { Purple Mt., } \\
\text { Nanjing }\end{array}$ & $P . m a+C . g l$ & 62 & 113 & $32^{\circ} 03^{\prime} 23.76^{\prime \prime} \mathrm{N}$ & $118^{\circ} 52^{\prime} 28.92^{\prime \prime} \mathrm{E}$ & SW15 & 12.5 & 250 \\
\hline Mixed II & $\begin{array}{l}\text { Purple Mt., } \\
\text { Nanjing }\end{array}$ & $P . m a+L . f o$ & 62 & 111 & $32^{\circ} 03^{\prime} 24.28^{\prime \prime} \mathrm{N}$ & $118^{\circ} 52^{\prime} 27.99^{\prime \prime} \mathrm{E}$ & SW10 & 16.4 & 275 \\
\hline Mixed III & $\begin{array}{l}\text { Purple Mt., } \\
\text { Nanjing }\end{array}$ & $P . m a+Q . v a$ & 62 & 127 & $32^{\circ} 03^{\prime} 44.14^{\prime \prime} \mathrm{N}$ & $118^{\circ} 52^{\prime} 15.65^{\prime \prime} \mathrm{E}$ & SW23 & 18.3 & 263 \\
\hline
\end{tabular}

Note: (1) Pure: pure coniferous forest. Mixed: coniferous-broadleaf mixed forest. (2) C.gl= Cyclobalanopsis glauca L.fo = Liquidambar formosana; Q.va = Quercus variabilis; P.ma = Pinus massoniana.

\subsection{Field Sampling}

In the coniferous-broadleaf mixed forest of Purple Mountain, the conifers are all Masson pines. According to the different associated broadleaf trees, we first selected three locations of coniferous-broadleaf mixed forests with Cyclobalanopsis glauca, Liquidambar formosana and Quercus variabilis, respectively, to establish sampled plots. Based on our field investigation, these forests can be largely divided into three layers: tree, shrub and herb layers. The tree layer is about 9-16 m in height and mainly consists of Masson pine and several dominant broadleaf trees including Cyclobalanopsis glauca, Ilex chinensis, Liquidambar formosana and Quercus variabilis, Mallotus apelta, etc. The shrub layer is about 2-3 $\mathrm{m}$ in height and comprises Lindera glauca, Ilex cornuta, Symplocos paniculata, Photinia serratifolia, etc. The herb layer is less than $1 \mathrm{~m}$ and mainly comprises Deyeuxia pyramidalis, Dryopteris fuscipes, Trachelospermum jasminoides, Semiaquilegia adoxoides, etc. In each sampling location, we set three plots of $20 \mathrm{~m} \times 20 \mathrm{~m}$ and then divided each plot into $165 \mathrm{~m} \times 5 \mathrm{~m}$ subplots (grids). Masson pine with $\mathrm{DBH} \geq 5 \mathrm{~cm}$ was chosen as the target tree species (reference tree) near or in the center of each grid. Meanwhile, all surrounding trees within the circle centered in reference tree with a radius of three meters were chosen as neighboring trees $(\mathrm{DBH} \geq 5 \mathrm{~cm}$ ). We then measured DBH, tree height, $\mathrm{FBH}$, crown breadth (east-west and north-south diameter) of reference and neighbor trees and the distance between them with caliper, tape meter and contracting height-meter following standard field procedures [15-18].

Prior to sampling, we found that Masson pines in the coniferous-broadleaf mixed forest were generally no more than six meters in crown breadth. Thus, we set three meters as the radius of the sampling circle. Accordingly, a set of data obtained in this manner comprised one reference tree and several neighboring trees. The tree centered in the circle with a radius of three meters is selected as a reference tree, the other three trees nearest to the center of the circle are identified as neighboring trees $[18,19]$. The reference trees and neighbors had to be at least $5.0 \mathrm{~cm}$ of DBH because most of the broadleaf trees were small-sized (Figure 2). In the same manner, we collected data such as the relevant parameters of Masson pines and neighboring trees in three $20 \mathrm{~m} \times 20 \mathrm{~m}$ sample plots in Longtan of Tianmuhu National Forest Park. In total, we obtained 100 sampling points in coniferous-broadleaf mixed forest and 46 sampling points in pure coniferous forest.

Meanwhile, we also calculated the live crown ratio, crown breadth and crown volume of target and neighboring trees in each sample point. The live crown ratio (LCR) was calculated as follows: LCR $=([$ tree height—first branch height $] /$ tree height) $[20,21]$. Crown breadth $(\mathrm{CB})$ was calculated as follows: $\mathrm{CB}=$ (east-west length $\mathrm{L} 1+$ north-south length L2)/2. Based on related literature and our investigation, the crown of Masson pine is approximately conical [22-24], and the crow of each dominant broadleaf tree species (i.e., Cyclobalanopsis glauca, Liquidambar formosana and Quercus variabilis) is approximately spherical $[1,25,26]$. Based on our field investigation, we noticed that about $1 / 5$ of the lower crown of the broadleaf tree was dead or vacant in the mixed forest stands. Thus, the crown volume of 
a broadleaf tree is calculated as $4 / 5$ of the volume of a sphere. Zhang et al. [27] pointed out that the bigger the crown length of Masson pine, the larger its crown volume, thereby increasing its photosynthetic capacity. We applied mean crown volume to indicate the leaf area for reference trees and their neighbors.

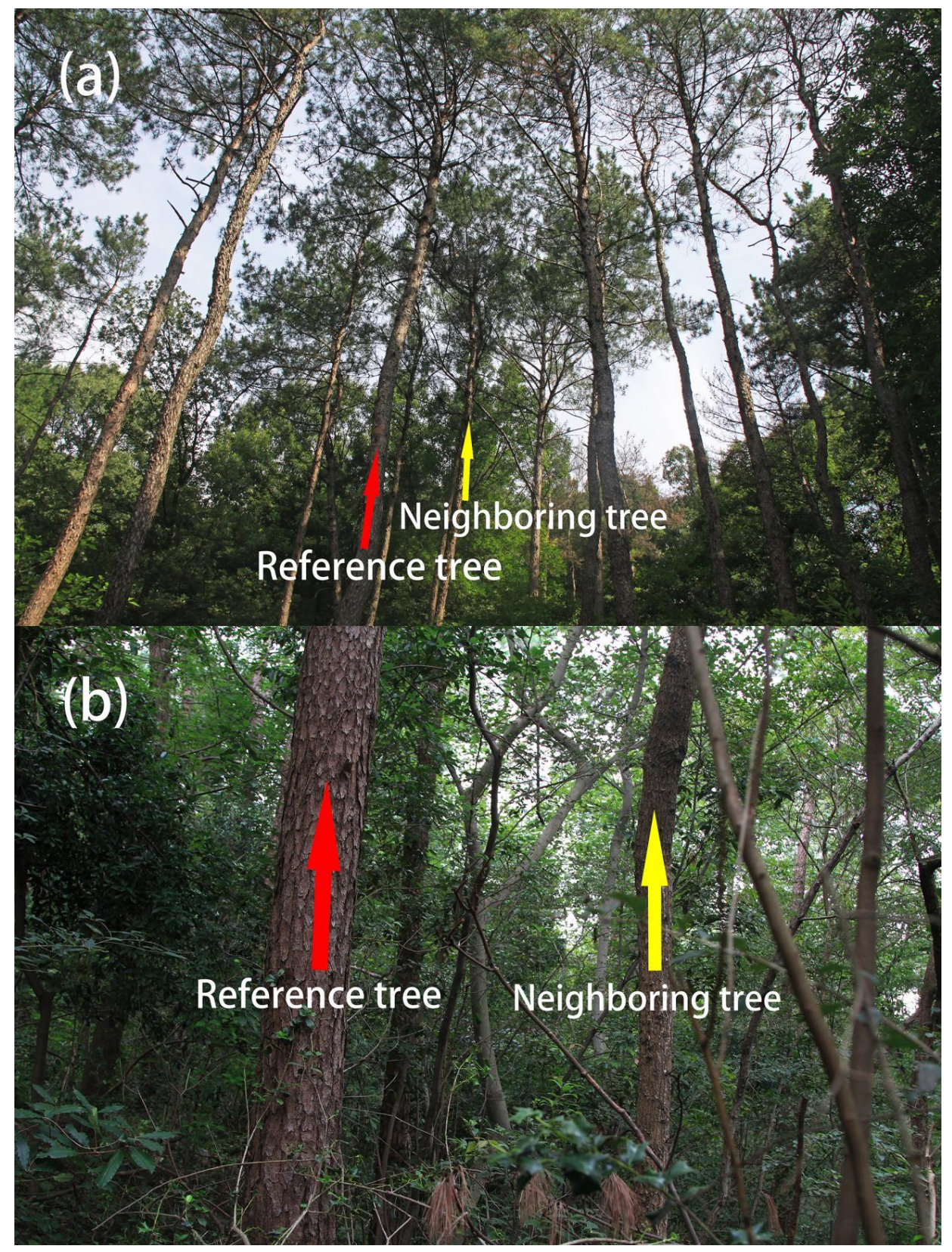

Figure 2. Reference tree Masson pine and its neighboring trees of a pine forest (a) in Longtan, Liyang, and counterparts of a mixed forest (b) in Purple Mountain, Nanjing, China. Reference and neighboring trees are indicated by the red arrows and the yellow ones, respectively. The photographs were provided by Guangfu Zhang.

Light intensity was measured by photometers (CEM DT-1308, Shenzhen Everbest Machinery Industry Co., Ltd., Shenzhen, China) simultaneously in coniferous forest and coniferous-broadleaf mixed forest. Five reference trees were chosen in four near-edge positions and the center of each plot of $20 \mathrm{~m} \times 20 \mathrm{~m}$ to measure light intensity; meanwhile, sampling points were set in the nearest open-air for comparison [28]. Three replicate measurements were performed at the height of $8.0 \mathrm{~m}, 9.5 \mathrm{~m}$ and $11.0 \mathrm{~m}$ above the ground but under the reference tree canopy at each sampling point, respectively (Figure 3) [29]. We 
first calculated the mean first branch height of reference trees in mixed forest to determine the middle position for measuring light intensity. Then, we set the other two locations above and below the position by the length of $1.5 \mathrm{~m}$, respectively. The measurements were taken on a clear day, while heavy-cloudy and rainy weathers were avoided. During a very short period (from 12:00 to 13:00), we finished all measurements in the two forest types [30].

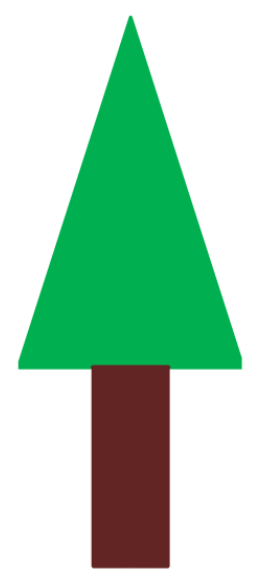

Pine forest

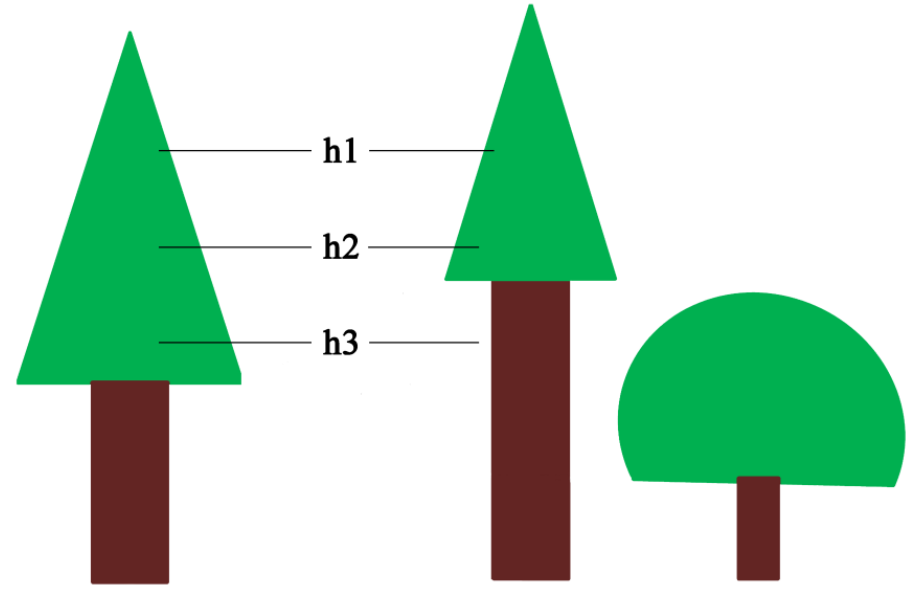

Mixed forest

Figure 3. The position diagram of light transmittance measurement of Masson pine in pine forest and mixed forest of southern Jiangsu, China. h1, h2 and h3 indicate the position with the height of $11.0 \mathrm{~m}, 9.5 \mathrm{~m}$ and $8.0 \mathrm{~m}$ above ground but under the reference tree canopy at each sampling point, respectively.

\subsection{Data Analysis}

We calculated the mean value and standard error of population growth traits (i.e., $\mathrm{DBH}$, tree height, FBH, LCR, CB and crown volume) of reference tree Masson pine and neighboring trees in two different types of forests. Firstly, one-way analysis of variance (ANOVA) was used to show the differences among growth performance of reference trees in pine forest, reference trees in mixed forest and neighboring trees in mixed forest, followed by least significant difference (LSD) post hoc tests. Secondly, we used a $t$-test to analyze the ratio of crown to trunk volume for reference trees between pine forest and mixed forest (or between reference trees and its neighboring trees in mixed forests). Thirdly, $t$-test was used to compare of light transmittance for reference trees between pine forest and mixed forest. Finally, $t$-test was applied to compare the difference in $\mathrm{FBH}$, the ratio of live crown ratio and distance between Masson pine and neighboring trees in both pine forest and mixed forest [31].

Moreover, we compared biomass synthesis and consumption of Masson pine in coniferous forest and coniferous-broadleaf mixed forest. The crown volume of Masson pine and adjacent broadleaf tree represents the synthesis volume of photosynthetic material, and the trunk volume is used as consumption volume of respiratory material. The trunk volume is calculated by the binary stand volume equation [32]. Light transmittance is a measure of light intensity under a reference tree canopy at a certain height vs. the counterpart for open air during the same period expressed as a percentage $[2,33]$.

We used MS-Excel 2016 and SPSS v22.0 software to make basic data processing and analysis (SPSS Inc., Chicago, IL, USA). Origin v8.0 software was used to draw boxplots (Origin Inc., Northampton, MA, USA).

\section{Results}

\subsection{Growth Performance of Masson Pine Populations in Pine Forest and Mixed Forest}

As shown in Table 2, there was no significant difference in the mean DBH of the reference tree Masson pines between pure pine forest plot (L1) and the three mixed (P1-P3) plots $(p>0.05)$. However, there were significant differences in the five indexes including 
tree height, FBH, LCR, $\mathrm{CB}$ and crown volume between the reference tree Masson pines in L1 plot and the counterparts in P1-P3 plots $(p<0.01)$. Furthermore, the LCR of reference trees in L1 plot was almost one and a half times as much as in P1-3 plots; crown volume in L1 plot was almost three times in P1-3 plots.

Table 2. Growth performance of Masson pine and broadleaf trees population in pine and mixed forests in southern Jiangsu, eastern China (mean $\pm \mathrm{SE}$ ).

\begin{tabular}{|c|c|c|c|c|c|c|c|}
\hline $\begin{array}{c}\text { Reference } \\
\text { (Neighboring) } \\
\text { Tree/Forest } \\
\text { Type }\end{array}$ & Individuals & DBH (cm) & $\begin{array}{c}\text { First Branch } \\
\text { Height (m) }\end{array}$ & $\begin{array}{l}\text { Tree Height } \\
\text { (m) }\end{array}$ & $\begin{array}{c}\text { Crown } \\
\text { Breadth (m) }\end{array}$ & $\begin{array}{l}\text { Live Crown } \\
\text { Ratio }\end{array}$ & $\begin{array}{l}\text { Tree Crown } \\
\text { Volume }\left(\mathrm{m}^{3}\right)\end{array}$ \\
\hline $\begin{array}{l}\text { Reference tree } \\
\text { Masson pine } \\
\text { /Pine forest }\end{array}$ & 46 & $31.61 \pm 0.82^{\mathrm{a}}$ & $9.46 \pm 0.33^{b}$ & $19.62 \pm 0.35^{\mathrm{a}}$ & $6.92 \pm 0.24^{\mathrm{a}}$ & $0.52 \pm 0.02^{b}$ & $139.51 \pm 10.18^{a}$ \\
\hline $\begin{array}{l}\text { Reference tree } \\
\text { Masson pine } \\
\text { /Mixed forest }\end{array}$ & 100 & $31.45 \pm 0.57^{\mathrm{a}}$ & $10.87 \pm 0.21^{a}$ & $16.86 \pm 0.25^{b}$ & $5.32 \pm 0.15^{b}$ & $0.35 \pm 0.01^{c}$ & $47.86 \pm 3.35^{c}$ \\
\hline $\begin{array}{l}\text { Neighboring } \\
\text { tree/Mixed } \\
\text { forest }\end{array}$ & 141 & $12.66 \pm 0.36^{\mathrm{b}}$ & $3.49 \pm 0.13^{c}$ & $8.86 \pm 0.18^{c}$ & $5.49 \pm 0.13^{b}$ & $0.61 \pm 0.01^{a}$ & $109.21 \pm 9.42^{b}$ \\
\hline
\end{tabular}

Note: Same lowercase letters in the same column indicate that there is no significant difference between different tree types, and different letters in the same column indicate significance at $p<0.01$ level.

The ratio of crown to trunk volume for reference tree Masson pine in pine forest was dramatically higher than in mixed forest, indicating the ratio of biomass synthesis to consumption in pine forest was much higher than in mixed forest (Figure 4a).
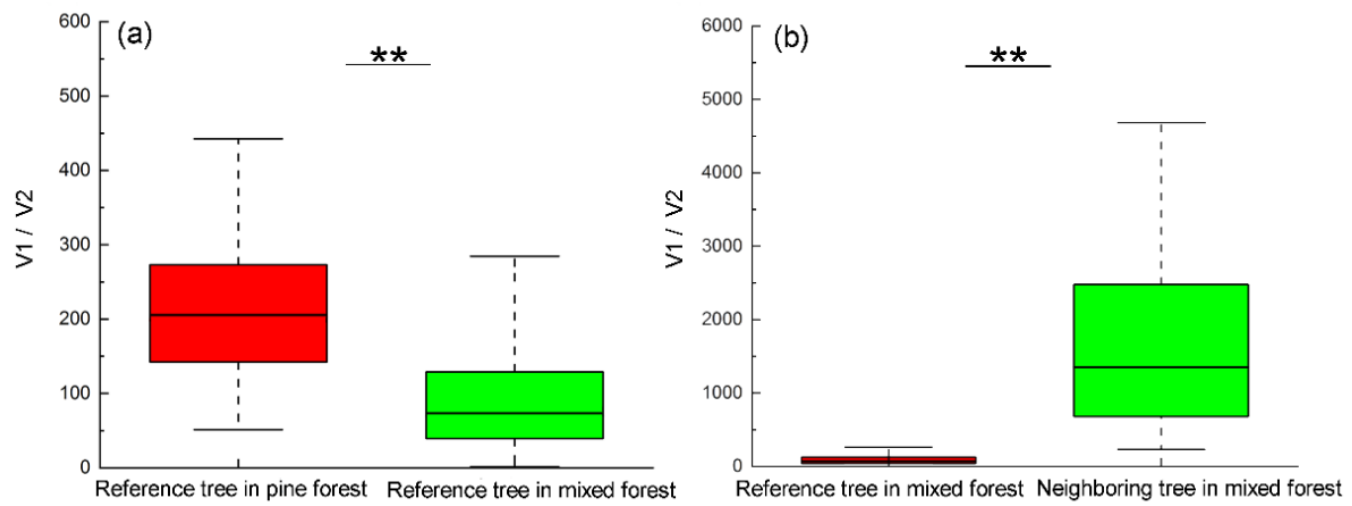

Figure 4. (a) The ratio of crown to trunk volume (V1/V2) for reference tree Masson pine in pine forest and mixed forest indicating the ratio of biomass synthesis to consumption. (b) The ratio of crown volume (V1/V2) between reference tree Masson pine and its neighboring trees in mixed forests indicating their ratio of biomass synthesis. ${ }^{* *}$ indicates significance at $p<0.01$ level.

\subsection{Growth Characteristics between Masson Pines and Dominant Broadleaf Trees in Mixed Forest}

All neighboring tree species around reference tree Masson pine were coniferous species in the plots of pine forest. On the other hand, all 25 neighboring tree species around reference tree Masson pine were broadleaf species in the plots of mixed forest. As shown in Table 2, the DBH, tree height, FBH, and LCR (except CB) between reference trees and their surrounding associated trees in the three forest stands had extremely significant differences $(p<0.01)$. Moreover, in mixed forest Masson pines, it was more than twice as large as their broadleaf neighboring trees in $\mathrm{DBH}$ while these pines only had approximately $1 / 25$ of their neighbors in tree crown volume (Table 2). Overall, there were significant differences between Masson pines and their neighbors in terms of the above four indexes (except CB) across the three mixed forest plots. 
In addition, a significant difference existed in the ratio of crown volume between reference tree Masson pine and its neighboring trees in mixed forests $(p<0.01)$, indicating that the ratio of biomass synthesis to consumption of the pines was much lower than their nearby broadleaf trees in mixed forest (Figure 4 b).

\subsection{Light Transmittance of Masson Pine Populations in Pine Forest and Mixed Forest}

Overall, reference tree Masson pines' light transmittance gradually decreased from h1 (i.e., $11.0 \mathrm{~m}$ ) to h2 (i.e., $9.5 \mathrm{~m}$ ) until h3 (i.e., $8.0 \mathrm{~m}$ ) in pine forest and mixed forest (Figure 5). There was no significant difference in light transmittance at the position of $11.0 \mathrm{~m}$ and $9.5 \mathrm{~m}$ $(p>0.05)$. However, a highly significant difference existed at the position of $8.0 \mathrm{~m}$ between pine forest and mixed forest $(p<0.01)$.

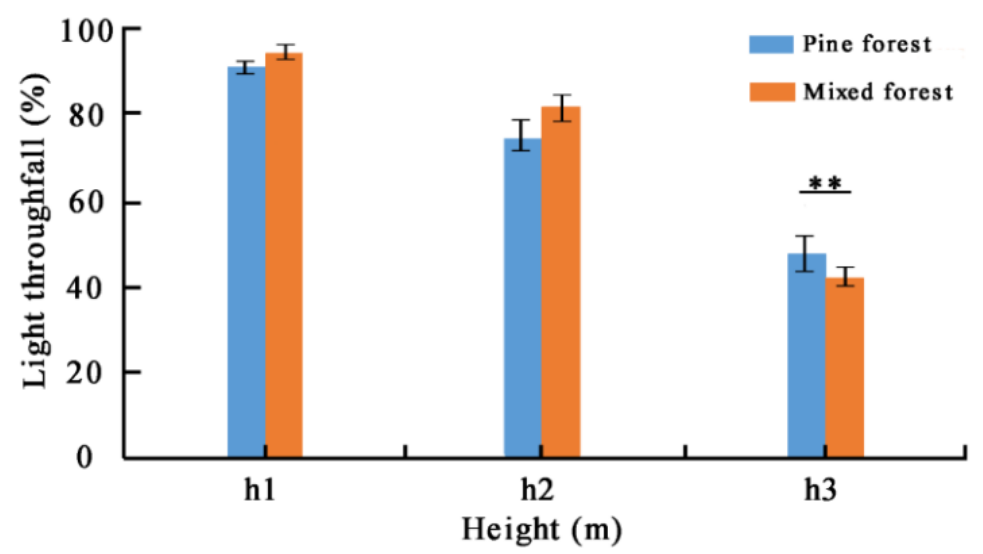

Figure 5. Comparison of light transmittance of three different positions for reference tree Masson pine in pure forest and mixed forest. ${ }^{* *}$ indicates significance at $p<0.01$ level.

Additionally, the mean distance between Masson pine and neighboring trees $(1.59 \mathrm{~m})$ in mixed forest plots was significantly shorter than that in pine forest plot $(2.77 \mathrm{~m})$ $(p<0.01)$ (Table 3).

Table 3. Comparison of the difference in $\mathrm{FBH}$, the ratio of live crown ratio and distance between Masson pine and neighboring trees in plots of pine forest and mixed forest in southern Jiangsu, eastern China (mean $\pm \mathrm{SE}$ ).

\begin{tabular}{|c|c|c|c|c|c|c|c|}
\hline \multirow{2}{*}{ Plot } & \multicolumn{3}{|c|}{ First Branch Height H (m) } & \multicolumn{3}{|c|}{ Live Crown Ratio } & \multirow{2}{*}{$\begin{array}{c}\text { Distance } \\
\text { between } P . m a \\
\text { and NT (m) }\end{array}$} \\
\hline & P.ma & NT & $\Delta \mathbf{H}$ & $P . m a(\mathrm{R})$ & NT ( $\left.\mathbf{R}^{\prime}\right)$ & $\mathbf{R}: \mathbf{R}^{\prime}$ & \\
\hline P1 & $\begin{array}{c}11.41 \pm 0.32 \\
(n=31)\end{array}$ & $\begin{array}{c}2.86 \pm 0.20 \\
(n=44)\end{array}$ & $\begin{array}{c}8.51 \pm 0.32 * * \\
(n=44)\end{array}$ & $\begin{array}{c}0.36 \pm 0.04 \\
(n=31)\end{array}$ & $\begin{array}{c}0.63 \pm 0.04 \\
(n=44)\end{array}$ & $\begin{array}{c}0.62 \pm 0.05^{* *} \\
(n=44)\end{array}$ & $\begin{array}{c}1.54 \pm 0.10^{* *} \\
(n=44)\end{array}$ \\
\hline $\mathrm{P} 2$ & $\begin{array}{c}10.17 \pm 0.43 \\
(n=31)\end{array}$ & $\begin{array}{c}3.44 \pm 0.19 \\
(n=45)\end{array}$ & $\begin{array}{c}6.92 \pm 0.38^{* * *} \\
(n=45)\end{array}$ & $\begin{array}{c}0.39 \pm 0.03 \\
(n=31)\end{array}$ & $\begin{array}{c}0.61 \pm 0.03 \\
(n=45)\end{array}$ & $\begin{array}{c}0.38 \pm 0.01 \\
(n=45)\end{array}$ & $\begin{array}{c}1.42 \pm 0.08^{* *} \\
(n=45)\end{array}$ \\
\hline P3 & $\begin{array}{c}10.96 \pm 0.29 \\
(n=38)\end{array}$ & $\begin{array}{c}4.06 \pm 0.23 \\
(n=52)\end{array}$ & $\begin{array}{c}6.89 \pm 0.25^{* *} \\
(n=52)\end{array}$ & $\begin{array}{c}0.31 \pm 0.03 \\
(n=38)\end{array}$ & $\begin{array}{c}0.58 \pm 0.04 \\
\quad(n=52)\end{array}$ & $\begin{array}{c}0.53 \pm 0.03^{* *} \\
(n=52)\end{array}$ & $\begin{array}{c}1.85 \pm 0.10 * * \\
\quad(n=52)\end{array}$ \\
\hline $\begin{array}{c}\text { P1-3 } \\
\text { (In total) }\end{array}$ & $\begin{array}{c}10.87 \pm 0.21 \\
(n=100)\end{array}$ & $\begin{array}{c}3.49 \pm 0.13 \\
(n=141)\end{array}$ & $\begin{array}{c}7.40 \pm 0.19^{* *} \\
(n=141)\end{array}$ & $\begin{array}{c}0.35 \pm 0.01 \\
(n=100)\end{array}$ & $\begin{array}{c}0.61 \pm 0.01 \\
(n=141)\end{array}$ & $\begin{array}{c}0.46 \pm 0.02 \text { ** } \\
(n=141)\end{array}$ & $\begin{array}{c}1.59 \pm 0.06^{* *} \\
(n=141)\end{array}$ \\
\hline L1 & $\begin{array}{c}9.58 \pm 0.44 \\
(n=46)\end{array}$ & $\begin{array}{c}9.00 \pm 0.49 \\
(n=32)\end{array}$ & $\begin{array}{c}0.58 \pm 0.5 \\
(n=32)\end{array}$ & $\begin{array}{c}0.52 \pm 0.02 \\
(n=46)\end{array}$ & $\begin{array}{c}0.52 \pm 0.02 \\
(n=32)\end{array}$ & $\begin{array}{c}1.05 \pm 0.05 \\
(n=32)\end{array}$ & $\begin{array}{c}2.77 \pm 0.18 \\
(n=32)\end{array}$ \\
\hline
\end{tabular}

Note: (1) ** indicates significance between mixed forest plots (marked as P1, P2 and P3) and pine forest plot (marked as L1) $(p<0.01)$. (2) $\Delta \mathrm{H}$ : the difference in first branch height between Pinus massoniana and its neighboring trees; R:R' refers to the ratio of live crown ratio between Masson pine and its neighboring trees. (3) P.ma = Pinus massoniana; NT = Neighboring Trees. 


\section{Discussion}

\subsection{Why Do Masson Pines Die during Forest Succession?}

The results of this study support our hypothesis that population decline of Masson pines in coniferous-broadleaf mixed forests is ascribed to the shading of broadleaf trees nearby, thereby causing the lower branches of Masson pines to die. With the continuous growth of broadleaf trees, the canopy of Masson pine is shrinking and its leaf area is decreasing, which ultimately renders the biomass synthesis of Masson pine less than its consumption and finally results in the death of Masson pines. This is consistent with the phenomenon that Masson pine population significantly decreases during the succession stage from coniferous forest to coniferous-broadleaf mixed forest, which is reported in previous studies $[1,2,11]$. Our results indicate that population decline of Masson pines may be related to intense competition from surrounding broadleaf trees because the mean distance between Masson pines and neighboring trees $(1.59 \mathrm{~m})$ in mixed forest plots was significantly shorter than in pine forest plots $(2.77 \mathrm{~m})$ (Table 3$)$. Thus, the reference tree in mixed plots had worse growth performances than that in pure pine plots (Table 2).

First of all, since broadleaf trees appeared much later in the succession process than Masson pines, these broadleaf trees adjacent to Masson pines in the coniferous-broadleaf mixed forest were generally lower than Masson pines (Table 2). Moreover, broadleaf trees have lower light transmittance, higher light saturation point, lower light compensation point and higher maximum photosynthetic rate relative to the pines [34-36]. Accordingly, they are able to grow normally under the pines' canopy with poor light. However, as an extremely sun-acclimated tree species, Masson pines have higher light transmittance, lower light saturation point, higher light compensation point and lower maximum photosynthetic rate [37]. When the canopy of broadleaf trees shades the pines' lower branches, which can hardly endure such low light intensity or even be unsurvivable, Masson pines' branches gradually wither and fall off the pole from the lower to upper parts.

Secondly, in general, broadleaf trees can grow well under coniferous trees, but coniferous trees may grow poorly under broadleaf trees during early forest succession in eastern China. According to our field observations, when broadleaf trees grow to a certain height, they will inevitably induce the experience of lower branches of coniferous trees relative to the stress of light. As conifers grow taller and taller, their FBH rises higher and higher. The FBH of conifers in the mixed forest rises much more quickly than in the pure coniferous forests. This will cause Masson pines in a mixed forest to gradually reduce their photosynthetic synthesis and gradually increase their breathing consumption. As the process continues, for Masson pines, their material synthesis per unit time will be eventually be less than their material consumption (Figure 4), thus causing a decline of Masson pine population in the mixed forest.

Some researchers have long suspected that soil change was responsible [2]. However, recent studies have found that Masson pines could grow better at fertile soil although it can endure poor soil [5]. With ongoing time, progressive succession is favorable for increasing the amount of soil organic matter and thereby improving soil physical environment [1]. This is conducive to the growth of Masson pines. Therefore, we conclude that the change of soil conditions may not be the major reason for the decline of Masson pines during the succession process.

Similarly, insect pests seem unlikely to be a major cause of Masson pines' population decline. When pines infect "pine wilt disease" caused by the nematodes (i.e., Bursaphelenchus xylophilus), their needles begin to turn yellow or rusty and then wither. Accordingly, the entire Masson pine will die within two or three months [38]. According to our field investigation (Figure 2), it was found that there are still green needles in the upper part of Masson pines in the plots, and only the lower branches near the crown of surrounding broadleaf trees wilt or fall off. 


\subsection{Implications for Population Dynamics and Forest Succession}

To the best of our knowledge, this is the first study to explain population decline of Masson pines in coniferous-broadleaf mixed forests using the theory that gradual growth of neighboring broadleaf trees results in a continuous rise in first branch height of Masson pines and thereby a decrease in their leaf area.

In the subtropical region of China, in addition to Masson pine, the same phenomenon is also discovered in other coniferous species such as Pinus taiwanensis, Pinus yunnanensis, etc. $[33,39,40]$; that is, the population number of conifers decreased continuously in response to light stress during progressive succession. This may be ascribed to similar "encroached phenomenon" that coniferous trees' branches from lower to upper gradually wither resulting from shading of broadleaf trees nearby.

In addition, in other countries or regions such as Japan, Pinus is also replaced by Alnus, Mallotus, Styrax and other shade tolerant species during forest succession [41]. The second example is from the secondary succession in an abandoned old field of southeastern Spain. If, in the absence of fire, forest vegetation is dominated by pioneer species such as Pinus halepensis, it will eventually be replaced by Quercus spp. over time [42]. For another example, in the south of the Mediterranean, middle and late succession species such as Quercus pubescens and Fagus sylvatica will also replace pioneer species such as Pinus [43].

For forest succession, its species composition varies in different parts of the world; hence, its succession trend is the combined result of different effects. Collectively, dominant conifers may be replaced by shade-tolerant broadleaf trees in the early stage of succession. In this study, our results have demonstrated that the shading effect of adjacent broadleaf trees on the lower branches of pioneer conifers plays an important role in mixed forest, ultimately resulting in population decline of conifers during early succession. This provides a new perspective for future research on forest succession mechanisms.

\section{Conclusions}

In summary, our study shows a considerable difference in growth performance between Masson pines (Pinus massoniana) and neighboring trees in coniferous-broadleaf mixed forests compared with coniferous forests. We have demonstrated for the first time that the population decline of Masson pines is affected by shade-tolerant broadleaved late-successional species, which can be primarily attributed to the distinctive light transmittance of dominant species nearby (pine forest vs. mixed forest). Our findings highlight the influence of sustained low light stress of dominant tree species on forest succession process. This study provides a new perspective for future studies on the mechanism of forest community succession; however, more studies are needed to confirm the mechanism in other forest communities.

Author Contributions: Y.S.: Performed experiments, data analysis and writing—original draft. G.Y.: Data analysis and writing-original draft. G.Z.: Conceived the study, performed the experiments and led writing. All authors have read and agreed to the published version of the manuscript.

Funding: This work was supported by Investigation and monitoring of rare and endangered plants in Jiangsu (211100B52003).

Data Availability Statement: Data available for research upon request.

Acknowledgments: We thank Wei Zhu, Zhenyu Zan, Kaidi Li and Xue Feng Wang for their assistance in field work. We thank Shucun Sun for his valuable advice on an earlier draft of the manuscript. We thank the anonymous reviewers for their constructive comments on the manuscript.

Conflicts of Interest: The authors declare no conflict of interest.

\section{References}

1. Song, Y.C. Evergreen Broad-Leaved Forests in China: Classification, Ecology, Conservation; Science Press: Beijing, China, 2013.

2. Dong, M. Population structure and dynamics of Pinus massoniana Lamb. on Mount Jinyun, Sichuan, China. Vegetatio 1987, 72, 35-44. [CrossRef] 
3. Zhang, Z.; Jin, G.Q.; Feng, Z.P.; Sun, L.S.; Zhou, Z.C.; Zheng, Y.; Yuan, C.Z. Joint influence of genetic origin and climate on the growth of Masson pine (Pinus massoniana Lamb.) in China. Sci. Rep. 2020, 10, 4653. [CrossRef]

4. Wu, Z.Y. The Vegetation of China; Science Press: Beijing, China, 1980.

5. Qin, G.F.; Zhou, Z.C. Germplasm Resources of Chinese Masson Pine; China Forestry Publishing House: Beijing, China, 2012.

6. Ding, S.Y.; Song, Y.C. Declining causes of Pinus massoniana in the processes of succession of evergreen broad-leaved forest. Acta Bot. Sin. 1998, 40, 755-760. [CrossRef]

7. Chen, Z.Q.; Peng, S.L.; Ni, G.Y.; Wei, X.Y. Effects of Pinus massoniana on germination of trees spp. in forest succession in South China. Allelopath. J. 2006, 17, 287-295.

8. Zhang, Q.; Chen, Y.J.; Song, L.Y.; Liu, N.; Sun, L.L.; Peng, C.L. Utilization of lightflecks by seedlings of five dominant tree species of different subtropical forest successional stages under low-light growth conditions. Tree Physiol. 2012, 32, 545-553. [CrossRef]

9. Egler, F.E. Vegetation science concepts I. Initial floristic composition, a factor in old field vegetation development with 2 figs. $J$. Plant Ecol. 1954, 4, 412-417. [CrossRef]

10. Pulsford, S.A.; Lindenmayer, D.B.; Driscoll, D.A. A succession of theories: Purging redundancy from disturbance theory. Biol. Rev. 2016, 91, 148-167. [CrossRef] [PubMed]

11. Fang, W.; Peng, S.L. Changes of tree species in the succession process of Pinus massoniana community in Dinghushan, Guangdong, P.R. China. J. Trop. Subtrop. Bot. 1995, 3, 30-37.

12. Hao, R.M.; Wei, H.T. Succession tendency of Zhongshan vegetation and discussion of possibility of reconstructing evergreen and deciduous broad-leaved mixed forest. Acta Phytoecol. Sin. 1999, 23, 108-115.

13. Chen, X.; Yuan, Z.X.; Jin, X.M.; Guan, Q.W.; Zhu, J.; Dai, K.L.; Zhao, C. Niche characteristic of main plant populations in a coniferous and broad-leaved mixed forest on Zijin mountain. J. Cent. South Univ. For. Technol. 2020, 40, 113-119.

14. Peng, X.L.; Ren, X.J.; Zhang, G.F.; Li, L.; Yang, T. Population structure and regeneration of Emmenopterys henryi in different patches in mountainous area of southern Jiangsu. Chin. J. Ecol. 2017, 36, 2716-2724. [CrossRef]

15. Condit, R.S.; Hubbell, S.P.; LaFrankie, J.V.; Sukumar, R.; Manokaran, N.; Foster, R.B.; Ashton, M.S. Species-area and speciesindividual relationships for tropical trees: A comparison of three 50-ha plots. J. Ecol. 1996, 84, 549-562. [CrossRef]

16. Li, W.; Zhang, G.F. Population structure and spatial pattern of the endemic and endangered subtropical tree Parrotia subaequalis (Hamamelidaceae). Flora 2015, 212, 10-18. [CrossRef]

17. Zhang, G.F.; Li, Q.; Hou, X. Structural diversity of naturally regenerating Chinese yew (Taxus wallichiana var. mairei) populations in ex situ conservation. Nord. J. Bot. 2018, 36, njb-01717. [CrossRef]

18. Liu, J.; Zhang, G.F.; Li, X. Structural diversity and conservation implications of Parrotia subaequalis (Hamamelidaceae), a rare and endangered tree species in China. Nat. Conserv. 2021, 44, 99-115. [CrossRef]

19. Ruprecht, H.; Dhar, A.; Aigner, B.; Oitzinger, G.; Klumpp, R.; Vacik, H. Structural diversity of English yew (Taxus baccata L.) populations. Eur. J. Forest Res. 2010, 129, 189-198. [CrossRef]

20. Zarnoch, S.J.; Bechtold, W.A.; Stolte, K.W. Using crown condition variables as indicators of forest health. Can. J. For. Res. 2004, 34, 1057-1070. [CrossRef]

21. Kuprevicius, A.; Auty, D.; Achim, A.; John, P.C. Quantifying the influence of live crown ratio on the mechanical properties of clear wood. Forestry 2013, 86, 361-369. [CrossRef]

22. Qin, G.F. Cultivation and Utilization of Masson Pine; Jindun Publishing House: Beijing, China, 1997.

23. Montgomery, R.; Chazdon, R.L. Forest structure, canopy architecture, and light transmittance in tropical wet forests. Ecology 2001, 82, 2707-2718. [CrossRef]

24. Meng, S.X.; Lieffers, V.J.; Huang, S. Modeling crown volume of lodgepole pine based upon the uniform stress theory. For. Ecol. Manag. 2007, 251, 174-181. [CrossRef]

25. Zhang, H.; Lai, P.Y.; Jim, C.Y. Species diversity and spatial pattern of old and precious trees in Macau. Landsc. Urban Plan 2017, 162, 56-67. [CrossRef]

26. Zhu, Z.H.; Kleinn, C.; Nölke, N. Assessing tree crown volume-A review. Forestry 2021, 94, 18-35. [CrossRef]

27. Zhang, P.; Wang, X.J.; Gao, Z.X.; Xu, H.; Wu, W.H.; Wang, Y.R.; Liu, L. Optima crown diameter models for Pinus massoniana in Jiangle, Fujian Province. J. Northwest For. Univ. 2015, 30, 94-98. [CrossRef]

28. Wei, H.X.; Chen, X.; Chen, G.S.; Zhao, H.T. Foliar nutrient and carbohydrate in Aralia elata can be modified by understory light quality in forests with different structures at Northeast China. Ann. For. Res. 2019, 62, 125-137. [CrossRef]

29. Chen, J.; Xu, M.; Zou, X.; Yang, Y.L.; Yan, L.B.; Zhang, J. The microclimatic characteristics of Pinus massoniana in different succession stages in Central Guizhou. China Environ. Sci. 2019, 39, 5264-5272. [CrossRef]

30. Rola, K.; Plášek, V.; Rożek, K.; Zubek, S. Effect of tree species identity and related habitat parameters on understorey bryophytesinterrelationships between bryophyte, soil and tree factors in a 50-year-old experimental forest. Plant Soil 2021, 466, 613-630. [CrossRef]

31. Xue, W. SPSS Statistical Analysis and Application, 2nd ed.; Publishing House of Electronics Industry: Beijing, China, 2011.

32. Zeng, W.S. Validation of two-variable tree volume tables for main tree species in China. For. Res. Manag. 2018, 5, 35-41. [CrossRef]

33. Zhang, L.Q. Population structure and dynamics of Pinus taiwanensis Hayata at Songyang county, Zhejiang Province, China. Vegetatio 1990, 86, 119-129. [CrossRef]

34. Zhang, J.; Shi, Y.J.; Zhu, Y.Q.; Liu, E.B.; Li, M.; Zhou, J.P.; Li, J.G. The photosynthetic carbon fixation characteristics of common tree species in northern Zhejiang. Acta Ecol. Sin. 2013, 33, 1740-1750. [CrossRef] 
35. Guan, M.; Jin, Z.X.; Li, Y.L.; Wang, Q. Photo-ecological characteristics of the dominant plant species in the secondary forest surrounding Qiandao Lake, Zhejiang, China. Acta Ecol. Sin. 2015, 35, 2057-2066. [CrossRef]

36. Fan, Y.L.; Liu, H.M.; Hu, N.; Ding, S.Y. Photosynthetic characteristics of plant functional groups in forest ecosystem at the national natural reserve of FuNiu Mountain. Acta Ecol. Sin. 2016, 36, 4609-4616. [CrossRef]

37. Liu, X.X.; Zhang, M.R.; Wen, G.S.; Zhang, J.; Zou, L.L.; Wu, G. Photosynthetic characteristic for fifteen potted seedlings common to Zhejiang Province. J. Zhejiang AEF Univ. 2012, 29, 173-179. [CrossRef]

38. Gao, R.H.; Luo, Y.Q.; Shi, J. Effect of Pine wilt disease infection on leaf photosynthetic characteristics of Masson pine. For. Res. 2019, 32, 65-73. [CrossRef]

39. Tang, C.Q.; He, L.Y.; Su, W.H.; Zhang, G.F.; Wang, H.C.; Peng, M.C.; Wu, Z.L.; Wang, C.Y. Regeneration, recovery and succession of a Pinus yunnanensis community five years after a mega-fire in central Yunnan, China. For. Ecol. Manag. 2013, 294, 188-196. [CrossRef]

40. Tang, C.Q.; Shen, L.Q.; Han, P.B.; Huang, D.S.; Xu, H.M. Forest characteristics, population structure and growth trends of Pinus yunnanensis in Tianchi National Nature Reserve of Yunnan, southwestern China. Veg. Classif. Surv. 2020, 1, 7-20. [CrossRef]

41. Tang, C.Q.; Ohsawa, M. Ecology of subtropical evergreen broad-leaved forests of Yunnan, southwestern China as compared to those of southwestern Japan. J. Plant Res. 2009, 122, 335-350. [CrossRef] [PubMed]

42. Santana, V.M.; Baeza, M.J.; Marrs, R.H.; Marrs, R.H.; Vallejo, V.R. Old-field secondary succession in SE Spain. Plant Ecol. 2010, 211, 337-349. [CrossRef]

43. Kunstler, G.; Curt, T.; Lepart, J. Spatial pattern of beech (Fagus sylvatica L.) and oak (Quercus pubescens Mill.) seedlings in natural pine (Pinus sylvestris 1.) woodlands. J. For. Res. 2004, 123, 331-337. [CrossRef] 